\title{
Innovation in Healthcare Organizations: Concepts and Challenges to Consider
}

\author{
Breitner Gomes Chaves', Catherine Briand ${ }^{2}$ and Khayreddine Bouabida ${ }^{3}$
}

\begin{abstract}
Healthcare systems have become increasingly complex and have faced difficulties in finding solutions to emerging population needs. New technologies have allowed users to obtain the information they need at speed never seen before in human history. This fact has promoted reflection, change, and restructuration in large healthcare corporations' traditional management style, which seeks to incorporate in their business model elements more flexible and interactive in connection with the recent challenges and the current healthcare trends. Promoting a creative and innovative culture in health organizations to allow the stakeholders to find solutions focused on healthcare systems' real needs is one of the most important elements to respond to emergent challenges. However, the development of mechanisms enhances a creative environment, and evaluative approaches that demonstrate the reliability and added value of innovations remain challenging. Therefore, this paper develops and recalls certain essential concepts that can help researchers, managers, and health workers interested in creating (or maintain) a favorable environment for innovation in healthcare organizations. The article also explores and clarifies some of the key critical elements of an innovation process from a strategic and organizational perspective, starting from contextual input elements favorable to its emergence until its evaluation stage.
\end{abstract}

Keywords: Organizational innovation, Creativity, Health evaluation.

\footnotetext{
1 Public Health School-University of Montreal and Research Center of the Institut universitaire en santé mentale de Montréal (PhD student).

2 Research Center of the Institut universitaire en santé mentale de Montréal and Université du Québec à Trois-Rivières (Québec, Canada).

${ }^{3}$ Public Health School, University of Montreal (PhD student).
}

Article Info: Received: May 13, 2021. Revised: May 28, 2021.

Published online: June 3, 2021. 


\section{Introduction}

Thousands of laboratories, incubators, accelerators, and startups are currently spending tremendous efforts to improve the health services users' experience and safety $(1,2)$. Hospitals, which traditionally have detained medical knowledge for so many years, have recently seen their knowledge possession overpassed by startups, forcing them to "move out of their comfort zone" to become more competitive and adapt to healthcare users emerging needs (3). New techniques of therapy and genetic modification, nanotechnology, non-invasive devices for continuous monitoring, artificial intelligence, and blockchain are examples of technologies increasingly incorporated by the world's health systems and services.

In this regard, large healthcare organizations progressively merge with startups and host or incubate new health tech businesses to actively face the emerging population's needs and participate in the sector's transformation process (4).

The emerging innovations are increasingly focused on wellness and prevention rather than illness. This process has forced the sector to transform from a traditional and predictable business model to a more flexible, adaptive, and sometimes even complex management model (5).

However, how will traditional health organizations adapt to the new needs of health systems and users? How to consider ethical dilemmas while innovating? How to incorporate new practices and mechanisms centered on the real needs of users? How to evaluate the relevance of new emerging technologies? What are the challenges of those innovation's implementation processes, particularly in supporting teams and healthcare professionals who wish to be innovative stakeholders? Why do specific innovation projects appear to be great ideas that fail during implementation and never see the light? This paper aims to promote among managers and health workers a reflection on these and other emerging issues of the health innovations field, providing fundamental bases to facilitate choices that really add value to all parties involved in the innovation process, especially future users.

\section{Innovation: a concept in transformation}

The capacity to develop new ideas and innovations has become a priority for many organizations. Intense global competition, the growing expectations of society, and technological development have made innovation a critical resource in competing. Nevertheless, what is innovation, after all? Although the term effectively derives from the Latin word "innovare," which means "to renew, to change," many authors define innovation differently, not a single consensual concept. To illustrate that, Table 1 shows some of the most often definitions available in the literature. 
Table 1 : Innovation Definitions

\begin{tabular}{|c|c|}
\hline AUTHOR & DEFINITION \\
\hline Schumpeter (1934) & $\begin{array}{l}\text { Development of a new product or changes in an existing } \\
\text { product. } \\
\text { - A new production process } \\
\text { - The discovery of a new market } \\
\text { - Development of new sources of supply with raw materials }\end{array}$ \\
\hline Simmonds (1986) & $\begin{array}{l}\text { Innovations are new ideas consisting of new products and } \\
\text { services, modern use of existing products, new markets for } \\
\text { existing products, or new marketing methods. }\end{array}$ \\
\hline Van de Ven (1986) & $\begin{array}{l}\text { Innovation is the development and implementation of new } \\
\text { ideas. }\end{array}$ \\
\hline Damanpour (1999) & The development and adoption of new ideas by a company. \\
\hline $\begin{array}{l}\text { Covin \& Slevin (1991), } \\
\text { Knox (2002), Lumpkin } \\
\text { \& Dess (1996) }\end{array}$ & $\begin{array}{l}\text { Innovation can be defined as a process that provides added } \\
\text { value and a degree of novelty to the organization, suppliers, } \\
\text { and customers, developing new procedures, solutions, } \\
\text { products and services, and new forms of marketing. }\end{array}$ \\
\hline Nohria \& Gulati (1996) & $\begin{array}{l}\text { Any policy, structure, method, process, product, or market } \\
\text { opportunity that a business unit manager perceives as new. }\end{array}$ \\
\hline Brunet (2015) & $\begin{array}{l}\text { Innovation in healthcare consists of a process of change and } \\
\text { continuous improvement of individual and collective } \\
\text { performance. }\end{array}$ \\
\hline
\end{tabular}

There is a particular variation between the definitions in Table 1. However, those definitions consider the character of "novelty" of products, services, processes, and ideas. It can also be seen as a change (or transformation), an approach of management and implementation, a method of organization, opening new "segments," or improving an existing one. There is also a tremendous conceptual variation in the health sector, and such perspectives may still vary among the private, public, third sector, and so on.

Thus, we instead adopt a vision of innovation as a complex social process in constant development, aiming to create more value for stakeholders. From a health systems perspective, the innovation path should be a process that aims to change and improve the population's health (6). It is worth highlighting a growing and crucial concept nowadays, which is "responsible innovation." The studies on responsible innovation in the health sector aim to reinforce the importance of aligning innovation processes and results with society's values, involving a wide range of stakeholders from its initial phase (7). 


\section{How to promote innovation in healthcare organizations?}

What makes some health organizations have an internal environment more propitious to creativity and innovation? Innovation is a complex social process that emerges from the dynamic interaction of several contextual factors in a given environment. Thus, it is natural to expect that individual, organizational, cultural, economic, and political elements can positively or negatively influence the emergence, implementation, and dissemination of innovations.

Before discussing factors favorable to organizational creativity, it is essential to understand better the concept of creativity. Although it is a concept of many possible meanings, theorists agree that creativity carries the idea of a "useful novelty" (8, 9). For Amabile (1988), creativity would result from a new and helpful idea developed by an individual or group of actors working together. Consequently, creativity is a critical element to promote innovation in healthcare organizations.

Individual and organizational factors are broadly described as facilitators or barriers elements of creativity and innovation.

Moreover, many of these factors related to individuals have been used as criteria by prominent health organizations' recruitment sectors worldwide. Psychometrics characteristics of individuals such as behavior, self-motivation, problem-solving, political, and social competencies are well documented as keys elements in identifying potentially creative individuals $(10,11)$.

However, since organizations seek to use rigorous criteria to select, recruit, and invest in individuals, organizations should also comprehend that organizational factors may influence catalyzing or inhibiting the individuals and the collective's creative capacity. Several conceptual models have proposed ways to analyze factors that facilitate or inhibit the emergence and diffusion of innovations (12). In Table 2 , we highlight some organizational characteristics considered favorable to the emergence of innovations. 
Table 2: Factors that promote or inhibit creativity and innovation in health organizations

\begin{tabular}{|l|l|}
\hline \multicolumn{1}{|c|}{$\begin{array}{c}\text { FACTORS THAT PROMOTE } \\
\text { CREATIVITY }\end{array}$} & \multicolumn{1}{c|}{$\begin{array}{c}\text { FACTORS THAT INHIBIT } \\
\text { CREATIVITY }\end{array}$} \\
\hline Autonomy for the use of resources & $\begin{array}{l}\text { Lack of resources and excessive control of } \\
\text { means to develop activities }\end{array}$ \\
\hline Good project management methodology & $\begin{array}{l}\text { Incipient and non-transparent project } \\
\text { management }\end{array}$ \\
\hline Enough resources & Lack of investment by the organization \\
\hline $\begin{array}{l}\text { Valuing new ideas and a collaborative } \\
\text { environment }\end{array}$ & Lack of internal cooperation \\
\hline Motivated and supportive managers & Apathy and lack of enthusiasm \\
\hline $\begin{array}{l}\text { Adequate time for reflection and search for } \\
\text { solutions to problems }\end{array}$ & $\begin{array}{l}\text { Absence of time for reflection, work } \\
\text { overload, and unreal timelines }\end{array}$ \\
\hline Culture of tolerance to errors and risks & $\begin{array}{l}\text { Intolerance to risk, resistance to change, } \\
\text { and emphasis on maintaining "status quo" }\end{array}$ \\
\hline $\begin{array}{l}\text { Management that focuses on understanding } \\
\text { individual behavior and needs }\end{array}$ & $\begin{array}{l}\text { Management that intensifies interpersonal } \\
\text { competition or defensive attitudes }\end{array}$ \\
\hline Coordination and collaboration of teams & Lack of clarity of organizational objectives \\
\hline Clear organizational objectives & Unclear organizational objectives \\
\hline Mechanisms to develop new ideas & $\begin{array}{l}\text { Closed management and criticizes new } \\
\text { ideas }\end{array}$ \\
\hline Participatory decision making & $\begin{array}{l}\text { Excessively centralized and controlling } \\
\text { management. }\end{array}$ \\
\hline
\end{tabular}

Source: Amabile (1988); Amabile \& Pratt (2016)

An environment that favors leadership autonomy seems to be one of the most critical elements for favoring creative processes. In contrast, an environment of excessive control and intolerance to error has been described as potentials organizational creativity barriers (13). Also, there is a consensus that a democratic, participative leadership style positively influences organizational creativity (14). However, many authors recognize a multi-factorial dynamic balance that requires health organizations to have a plan adapted to each context instead of merely believing in a magic recipe about the "paths of organizational creativity" (15). This plan should allow the emergence of various initiatives (sometimes top-down, sometimes bottom-up) with management support allowing time for reflection, trialand-error, and quality assessment criteria related to this creative and innovative capacity.

Besides, external factors such as public and private funding, government policies, and external legitimacy search may enhance and encourage innovation in some sectors.

They may even shape the organization's internal environment and its internal structure (16). Finally, having an internal or external environment propitious to 
innovation does not automatically lead to innovation success. We are going to clarify this element when evoking the implementation process later in this paper.

\section{Assessing the reliability and pertinence of an innovation}

One of the challenging exercises for healthcare organizations is establishing a list of specific criteria to evaluate the innovation before deciding on its incorporation and adoption. Many approaches and strategies are possible and routinely applied by numerous organizations around the world. However, in general, this can be done in two stages. First, local criteria are established to appreciate the relevance of innovations. Then, a criterion for prioritizing the innovations approved by the first step is established (6).

Failures can negatively impact the organization in this step. For instance, loss of resources, increase in unnecessary costs, loss of a competitive or market advantage, unjustified escalation of costs to health systems, and, even more troubling, the loss of a relevant social opportunity or even deleterious effects to users and, consequently, lawsuits (17). It becomes even more complicated when it comes from public funds, in which taxpayers expect exceptional public resource management. Thus, public organizations must consistently innovate in a responsible, efficient, transparent, and ethical way.

Assessing the real value of an innovation is not an easy task. It may require different strategies, depending on each type of innovation or innovation domain. Also, there is an intimate relationship between the evaluation process and stakeholders' values and culture.

Some strategies and elements should be considered as judging the pertinence of an innovation. We suggest a constructive reflection based on some basic questions.

The initial ten points for judging the pertinence of innovations in health organizations:

1. Does this innovation solve one or several problems in our organization?

2. Does this innovation meet the real needs of our patients or employees? Does it solve the identified problem?

3. Does it add value to our patients?

4. Is it ethical and responsible (respects the environment and local culture?)

5. Does it increase or reduce any form of social or health inequity?

6. Can we manage existing conflicts of interest?

7. Do different stakeholders (immediate managers, healthcare professionals, users) participate in the project from its initial phase?

8. Is this innovation compatible with our organization's values and mission (and health professionals and their respective professional associations)?

9. Are the implementation and operational costs assumable by our financial reality?

10. Is it possible to measure its effects and impacts? 
A practical strategy for evaluating innovation's pertinence and reliability is building "health innovation assessment units" (HIAU).

That type of organizational committee can judge the relevance of proposed innovations from a multidimensional analysis, considering multiple factors, such as the work process, economic, social, political, and cultural factors. Therefore, it is an interdisciplinary working group with different expertise, including patient representatives. This model is advisable in private institutions, but it is imperative in public organizations to implement new technologies responsibly and sustainably. For instance, in Quebec, Canada, public health organizations have had similar boards for years that judge the relevance of innovations to organizations, advising the acquisition or not of new technology (e.g., a new radiotherapy or imaging device) and evaluating the impact of changes on critical processes.

Another approach that can help evaluate the relevance or value of innovation is proposed by the research group "In fieri" from Montreal University. The researchers stress evaluating the value of innovation to society. They suggest a model based on nine dimensions, organized into five domains: value for the population health, value for the health system, value for the economy, organizational and environmental values (7). Regarding the criteria for evaluating the prioritization of innovations, health institutions should adopt more efficient models to define their priorities in implementing innovations. The dominant criterion of prioritization, based on the charisma of the institution's leader or communicative strategies of more influential people (sometimes with worrying conflicts of interest), should be replaced by transparent criteria in line with organizational and social objectives.

The "round of votes" is one of the most traditional methods for that. According to this method, each key actor member determines which innovations are more relevant from the conception phase (6). A shorter list is then offered again. This process can be repeated until a consensus is reached, usually in the third or fourth voting round. In this method, it is imperative to choose wisely the actors who will participate because it is an individual judgment.

The Hospital maternal-infant Saint-Justine de Montréal created a practical and straightforward method. The method consists of classifying the innovation projects according to a matrix of expected impact $X$ difficulty implementation. Thus, in the end, a prioritization is built based on a score with previously defined criteria.

Each organization can build systems similar to the one used by Saint-Justine Hospital, establishing criteria relevant for the organization and society. Institutions may also assign a relative weight to each criterion or dimension, building a final scoring system to support the prioritization process, that is, a multi-criteria system. In the end, projects are chosen according to their final scores. The advantage of these methods is transparency and the possibility of establishing pre-defined criteria according to interests, objectives, organizational and social values. 


\section{The challenge of implementing innovations}

Many promising health interventions fail to translate into meaningful patient care outcomes across multiple contexts (18). An innovative health intervention fails basically for three reasons, a failure of the implementation, a failure of the program theory, or a misjudgment of the leaders since the need to act has been identified (19). Therefore, the innovation implementation's success will depend on "the degree of change" and the transformation "accepted" by the environment. In other words, it results from a complex interaction of the innovation proposed, its acceptability by the environment, and elements of the organizational and external context.

An intervention with a robust theoretical foundation (good program theory) can be perceived as a failure when, in reality, it is an implementation problem. Similarly, a program with severe problems in its theoretical foundations can be perceived as a success. However, external and unexpected factors (e.g., confounding variables) had a preponderant influence on its effects. Although there is no consensus on the term, program theory is a set of assumptions that intend to explain how and under what circumstances an intervention produces its expected results (20). For others, the term is a synonym for "theory of change" (21).

Greenhalgh et al. (2004) conducted a systematic review of theoretical and empirical evidence on the determinants that may influence disseminating and implementing health organizations' innovations. This study proposes a framework that identifies a range of components related to innovation diffusion and implementation success, such as characteristics of the innovation itself, individual characteristics of opinion leaders ("adopters"), and organizational factors.

There are hundreds of different models that can serve as reference points for health workers and managers when planning the implementation of their innovations (12). For example, Rogers' diffusion model suggests ways to understand how "change" can be achieved in health organizations. This author argues that specific characteristics of innovation can facilitate its adoption. According to his theory, some factors can also influence innovation's acceptability, such as the degree of the proposed change, the compatibility with organizational values, the perception of necessity by involved parties, and flexibility or adaptability of the "solution" $(8,22)$. Rogers (2010) also described that the process of innovation diffusion has an "S" shaped dispersion pattern, that is, it has an initial slow phase affecting some members more "open," then a fast-intermediate phase with wide dispersion and, finally, a third slow phase at the end. Therefore, identifying key players in each phase and a communication strategy can contribute to the implementation's success. Besides, implementation science is an emerging field that aims to discover innovative methods that contribute to the deployment and implementation of innovations in various sectors and fields of knowledge (23).

In this sense, Damschroder et al. (2009) describe the "Consolidated Framework for Implementation Research" (CFIR) that offers an overarching typology to promote implementation theory development and verification about what "works," "where", and "why" under multiple contexts. 
It is also worth mentioning that health workers are not agents who passively receive innovations. In reality, they develop feelings (positives or negatives) about what is being proposed. They worry about the consequences; they want to modify them to fit specific tasks or redesign them (24).

Therefore, one fundamental element is understanding each actor's expectations involved in the process because certain innovations can propose changes that generate imbalances in power relationships established consciously or not (25). Thus, strategies adapted to each actor involved guiding before, during, and after implementing a new process or product are essential. Furthermore, managing change and fears of the actors involved concerning the new work process or technology proposed are fundamental for any project's success. Note that "the change" is a complex phenomenon, often unpredictable and that it can involve a wide range of "transformation agents" whose roles and implications may vary over time (19). Table 3 highlights some examples of expectations according to the actors.

Table 3: Actors' expectations in an innovation process

\begin{tabular}{|l|l|}
\hline \multicolumn{1}{|c|}{ ACTOR } & \multicolumn{1}{c|}{ EXPECTATION } \\
\hline $\begin{array}{l}\text { Health } \\
\text { Professionals }\end{array}$ & $\begin{array}{l}\text { Improvement of clinical results } \\
\text { Better diagnostics and treatments } \\
\text { Reduce time lost in administrative processes }\end{array}$ \\
\hline Patients & $\begin{array}{l}\text { Improve their experience and security } \\
\text { Wellness } \\
\text { Reduce time loss and delays }\end{array}$ \\
\hline $\begin{array}{l}\text { Health } \\
\text { Organizations }\end{array}$ & $\begin{array}{l}\text { Improve the efficiency of its internal processes } \\
\text { Improve productivity } \\
\text { Waste reduction } \\
\text { Improve clinical results and the quality of services } \\
\text { provided }\end{array}$ \\
\hline $\begin{array}{l}\text { Technology } \\
\text { companies }\end{array}$ & $\begin{array}{l}\text { Profitability } \\
\text { Reliable partnerships } \\
\text { Better clinical results }\end{array}$ \\
\hline $\begin{array}{l}\text { Regulatory } \\
\text { agencies }\end{array}$ & $\begin{array}{l}\text { Risk reduction } \\
\text { Improvement of patient safety. }\end{array}$ \\
\hline
\end{tabular}

Source : Omachonu \& Einspruch (2010)

Finally, while usually the reflection on the "rational" of the changes expected by an innovation (program or change theory) is carried out even before implementation (explicitly or implicitly), implementation's process and change management must be rigorously fallow in many stages. The implementation itself is not a static event; on the contrary, it must be seen as a "living," complex, and interactive process. Thus, people in charge must be prepared for necessary adaptations over time and according to the context. 


\section{The process of evaluating innovations}

Broadly, evaluation means making a "value judgment" about something (26). Despite the intense debate and progress of the sector over the last decades, health evaluation remains a significant challenge for health systems and organizations. One of these major challenges is to develop suitable approaches to measure or explain the effects attributed to an innovative intervention, explaining possible causal relationships between its effects and the intervention components.

So far, there is a multiplicity of strategies and theoretical perspectives on the subject, from linear models to complex multidimensional evaluation approaches (27). Of course, a "best" model does not exist, but the most suitable for a given context, the type of intervention proposed, and the evaluative objectives. Thus, the evaluation process of innovation is a fundamental stage and must be designed and executed rigorously.

In general, there are two types of evaluation: normative and evaluative research. The normative evaluation aims to evaluate the intervention according to preestablished criteria and norms. For example, hospital accreditation organizations usually apply a normative evaluation type to measure hospital processes based on existing norms or quality standards. Besides, regulatory agencies publish "gold standards" that must be followed and often assess products or processes' compliances.

Evaluative research aims to analyze and understand possible causal relationships using a scientific approach (28). In other words, this type of evaluation aims to understand the "how" and "why" of the results of particular interventions (29). For example, to analyze new medical device outcomes in a health care organization, it is necessary to use a scientific evaluation approach to verify whether there is an association or even a causal relationship between the new device and the observed effects. Table 4 summarizes some of the main possible types of innovation evaluation according to objectives and methodologies most commonly employed. 
Table 4: Types of evaluations of an innovation

\begin{tabular}{|c|c|c|}
\hline $\begin{array}{c}\text { TYPE OF } \\
\text { EVALUATION }\end{array}$ & OBJECTIVES & $\begin{array}{c}\text { COMMON } \\
\text { METHODOLOGIES }\end{array}$ \\
\hline Normative & $\begin{array}{l}\text { Evaluate conformity regarding } \\
\text { structure, processes, or results. }\end{array}$ & $\begin{array}{l}\text { Comparison with } \\
\text { standards, protocols, } \\
\text { consensus, and laws }\end{array}$ \\
\hline \multicolumn{3}{|c|}{ TYPES OF EVALUATIVE RESEARCH } \\
\hline Effects analyses & $\begin{array}{l}\text { Assess the efficacy of the } \\
\text { proposed innovation, ensuring } \\
\text { that the effects observed are due } \\
\text { to the proposed innovation }\end{array}$ & $\begin{array}{l}\text { Experimental or quasi- } \\
\text { experimental strategies }\end{array}$ \\
\hline $\begin{array}{l}\text { Production } \\
\text { analysis }\end{array}$ & $\begin{array}{l}\text { The analysis of production } \\
\text { studies the relationships } \\
\text { between the resources used } \\
\text { (means) and the volume and } \\
\text { quality of services produced } \\
\text { (activities) }\end{array}$ & $\begin{array}{l}\text { Methods derived from } \\
\text { the economic field, such } \\
\text { as cost accounting. }\end{array}$ \\
\hline $\begin{array}{l}\text { Efficiency } \\
\text { analysis }\end{array}$ & $\begin{array}{l}\text { It aims to study the relationships } \\
\text { between the resources and the } \\
\text { effects observed }\end{array}$ & $\begin{array}{l}\text { Economic analyses } \\
\text { (cost-benefit analysis, } \\
\text { cost-effectiveness } \\
\text { analysis, etc.) }\end{array}$ \\
\hline $\begin{array}{l}\text { Implementation } \\
\text { analysis }\end{array}$ & $\begin{array}{l}\text { It focuses on the relationships } \\
\text { between the intervention, its } \\
\text { components, and the context }\end{array}$ & $\begin{array}{l}\text { Case studies } \\
\text { Mixed methods }\end{array}$ \\
\hline
\end{tabular}

Source: Brousselle et al. (2011)

The evaluation process can be performed at any stage of the innovation cycle. Predicting all expected and unexpected results of an innovation is often a complex task, so evaluation must be rigorously planned. Unexpected effects often have significant repercussions on the adhesion of an innovation.

For instance, imagine a new clinical protocol that has demonstrated satisfactory clinical results according to pre-established criteria by only evaluating the efficacy/effectiveness dimension. However, its implementation has significantly increased the administrative/bureaucratic workload of the professionals involved. Gradually, they may begin to "avoid" the new protocol due to a perceived organizational work quality reduction. Adding qualitative elements (focus groups, interviews, observations, documental analysis, etc.) to the evaluation process consists of a powerful tool for collecting strategic information on institutional innovations to achieve a more realistic analysis.

Several evaluative works on health innovation suggested that the new approaches should develop and focus the following elements $(17,30)$, including co-construction models integrating patients, healthcare professionals, and other stakeholders: 
- Multidimensional approaches that study innovation simultaneously at the individual, group, and organizational levels.

- Combining quantitative and qualitative data.

- Use of longitudinal designs.

- Innovation both as a dependent and independent variable.

- Application of experimental designs when possible.

We also highlight the evaluative approach developed at the School of Public Health of the University of Montreal, the implementation analysis. This evaluation process aims to understand the influence of contextual dynamics on the proposed intervention and innovations in different phases of the implementation process or on its effects (19). This analytical and evaluative approach is indicated, for example, to facilitate the understanding of complex interventions whose results are little known or not expressive due to a possible influence of several interactive factors outside the intervention (contextual factors).

Although clinical trials are known as the gold standard for efficacy evaluation, such a design has many practical limits to being performed, such as costs, time available, ethical issues, and so forth. Thus, given these possible limits, the implementation analysis provides a way to assess the extent to which innovation has produced or influenced the observed results. Furthermore, such approaches open the "black box" of the intervention, examining the "how," "the context," "why," and for "whom" it has worked, making its reproduction in other contexts more tangible, as well as facilitating the necessary adaptations for implementation in other realities. However, the implementation analysis is not a specific method or technique but a way to structure and perform the evaluation process

\section{Conclusion}

Innovation and human creativity will continue to be the driving force behind the development of healthcare systems. New flexible strategies to organically enhance an innovative environment aligned with organizational and social values become imperative in the light of emerging challenges. This paper developed a reflection on the main elements contributing to fostering innovation in healthcare's complex organizational environment.

It also stressed some vital elements regarding innovation evaluation, particularly the implementation evaluation considering its importance to innovation success. Finally, this paper highlighted the essential concepts to consider in order to promote responsible and ethical innovations that do not accentuate existing inequalities. 


\section{Reference}

[1] Steinhubl, S.R., Muse, E.D. and Topol, E.J. (2013). Can mobile health technologies transform health care?

Jama. 310(22):2395-6.

[2] Leff, D.R., St John, E.R. and Takats, Z. (2017). Reducing the margins of error during breast-conserving surgery: disruptive technologies or traditional disruptions? Jama Surgery. 152(6):517-8.

[3] Abrams, D.B. (2014). Promise and peril of e-cigarettes: can disruptive technology make cigarettes obsolete? Jama. 311(2):135-6.

[4] Stey, A., Kanzaria, H. and Brook, R. (2018). How disruptive innovation by business and technology firms could improve population health. Jama. 320(10):973-4.

[5] Dionne, K.E, and Carlile, P. (2016). Le pouvoir transformationnel des hackathons. Gestion. 41(2):62-3.

[6] Brunet, F. (2015). L'innovation en santé: réfléchir et agir: Ed. du CHU SainteJustine.

[7] Silva, H.P, Lehoux, P., Miller, F.A. and Denis, J. L. (2018). Introducing responsible innovation in health: a policy-oriented framework. Health research policy and systems. 16(1):90.

[8] Rogers, E.M. (2010). Diffusion of innovations: Simon and Schuster.

[9] Stein, M.I. (2014). Stimulating creativity: Individual procedures: Academic Press.

[10] Mackinnon, D.W. (1965). Personality and the realization of creative potential. American Psychologist. 20(4):273-81.

[11] Barron, F. (1968). Creativity and personal freedom: Princeton, NJ: Van Nostrand.

[12] Wejnert, B. (2002). Integrating models of diffusion of innovations: A conceptual framework. Annual review of sociology. 28(1):297-326.

[13] Amabile, T.M. and Pratt, M.G. (2016). The dynamic componential model of creativity and innovation in organizations: Making progress, making meaning. Research in organizational behavior. 36:157-83.

[14] Nyström, H. (1990). Organizational innovation. 1990.

[15] Andriopoulos, C. (2001). Determinants of organisational creativity: a literature review. Management decision.

[16] Scott, W.R. (2013). Institutions and organizations: Ideas, interests, and identities: Sage publications.

[17] Heathfield, H., Pitty, D. and Hanka, R. (1998). Evaluating information technology in health care: barriers and challenges. Bmj. 316(7149):1959.

[18] Damschroder, L.J., Aron, D.C., Keith, R.E., Kirsh, S.R., Alexander, J.A., and Lowery, J.C. (2009). Fostering implementation of health services research findings into practice: a consolidated framework for advancing implementation science. Implementation Science. 4(1):50. 
[19] Champagne, F., Brousselle, A., Hartz, Z., Contandriopoulos, A., and Denis, J. A. (2011). Análise de implantação. Avaliação: conceitos e métodos Rio de Janeiro: Editora Fiocruz. 61-74.

[20] Chen, H.T. (1990). Theory-driven evaluations: Sage.

[21] Mackenzie, M. and Blamey, A. (2005). The practice and the theory: lessons from the application of a theories of change approach. Evaluation. 11(2):15168.

[22] Sanson-Fisher, R.W. (2004). Diffusion of innovation theory for clinical change. Medical journal of Australia. 180:S55-S6.

[23] Bauer, M.S., Damschroder, L., Hagedorn, H., Smith, J. and Kilbourne, A.M. (2015). An introduction to implementation science for the non-specialist. BMC psychology. 3(1):32.

[24] Greenhalgh, T., Robert, G., Macfarlane, F., Bate, P. and Kyriakidou O. (2004). Diffusion of innovations in service organizations: systematic review and recommendations. The Milbank Quarterly. 82(4):581-629.

[25] Crozier, M., Friedberg, E. (1977). L'acteur et le système.

[26] Brousselle, A., Champagne, F., Contandriopoulos, A.P. and Hartz, Z. (2011). Avaliação: conceitos e métodos. Avaliação: conceitos e métodos p. 291.

[27] Moullin, J.C., Sabater-Hernández, D., Fernandez-Llimos, F. and Benrimoj, S.I. (2015). A systematic review of implementation frameworks of innovations in healthcare and resulting generic implementation framework. Health Research Policy and Systems. 13(1):16.

[28] Contandriopoulos, A.P., Champagne, F., Denis, J.L. and Pineault, R. (1997). A avaliação na área da saúde: conceitos e métodos. Avaliação em saúde: dos modelos conceituais à prática na análise da implantação de programas.

[29] Chen, H.T. (2014). Practical program evaluation: Theory-driven evaluation and the integrated evaluation perspective: Sage Publications.

[30] Länsisalmi, H., Kivimäki, M., Aalto, P. and Ruoranen, R. (2006). Innovation in healthcare: a systematic review of recent research. Nursing science quarterly. 19(1):66-72. 